\title{
Proteolipid Protein Gene Product Can Be Secreted and Exhibit Biological Activity during Early Development
}

\author{
Masahisa Yamada, ${ }^{1}$ Anna Ivanova, ${ }^{1}$ Yoshihide Yamaguchi, ${ }^{1}$ Marjorie B. Lees, ${ }^{2}$ and Kazuhiro Ikenaka ${ }^{1}$ \\ ${ }^{1}$ Laboratory of Neural Information, National Institute for Physiological Sciences, Okazaki National Research Institutes, Aichi \\ 444-8585, Japan, and ²Biochemistry Division, E. K. Shriver Center, Waltham, Massachusetts 02254
}

\begin{abstract}
A gene encoding myelin proteolipid protein (PLP) and its smaller isoform DM20 is expressed at least 1 week before myelination. Mutations within the gene cause abnormalities in the development of premyelinating oligodendrocytes, resulting in hypomyelinating disorders. These findings suggest a premyelinating function of the PLP gene products. We previously demonstrated that PLP gene expression is directly associated with secretion of a factor that increases the number of oligodendrocytes. Here we show that this activity is mediated by a secreted fragment containing the C-terminal portion of PLP. This factor increased the bromodeoxyuridine incorporation rate
\end{abstract}

Myelin proteolipid protein (PLP) is one of the major proteins in CNS myelin and may function in stabilizing the myelin membrane. However, in many PLP mutants an abnormal phenotype is evident before the myelinating period (for review, see Skoff and Knapp, 1992). The abnormalities include early degeneration of oligodendrocytes, the myelin-forming cells in the CNS, cellular abnormalities in astroglia (Skoff, 1976), and increased axonal proteolysis (Nixon, 1982). Thus, mutations in the PLP gene seemed to exert pleiotropic effects on the development of the nervous system. Although proteins for PLP or its alternatively spliced variant, DM20, are found postnatally at a late stage of oligodendrocyte development (Levine et al., 1990), DM20 mRNA is found at early stages before myelination (Ikenaka et al., 1992; Timsit et al., 1992). The amino acid sequence of PLP is totally conserved among rat, mouse, and human (Mikoshiba et al., 1991); even a point mutation or a slight overexpression of the PLP gene causes severe effects on oligodendrocyte survival (Hudson and Nadon, 1992; Knapp, 1996). The jimpy mouse, one of the PLP mutants, splices out the fifth exon from the PLP mRNA (Nave et al., 1986; Moriguchi et al., 1987). Jimpy oligodendrocytes in culture, which normally degenerate, can survive and produce myelin membrane-like sheets after the addition of normal, but not jimpy, astrocyte conditioned medium (Bartlett et al., 1988; Knapp et al., 1992). This suggested that PLP gene expres-

\footnotetext{
Received Sept. 21, 1998; revised Dec. 31, 1998; accepted Jan. 8, 1999.

This work was supported by Grant in Aid 07279107 for Scientific Research on Priority Areas on "Functional Development of Neural Circuits" and Grant in Aid 07458207 from the Ministry of Education, Science, Sports, and Culture of Japan, by a grant from the National Center for Nervous, Mental, and Muscular Disorders of the Ministry of Health and Welfare of Japan, and by a grant from the Nissan Science Foundation. We thank Dr. Steve Pfeiffer for the gifts of antibodies and for critical reading of this manuscript. We are also grateful to Drs. Tetsushi Kagawa and Hiroko Baba for valuable discussion.

Correspondence should be addressed to Dr. Kazuhiro Ikenaka, National Institute for Physiological Sciences, Okazaki National Research Institutes, 38 Azanishigonaka, Myodaiji-cho, Okazaki, Aichi 444-8585, Japan.

Copyright (C) 1999 Society for Neuroscience $\quad 0270-6474 / 99 / 192143-09 \$ 05.00 / 0$
}

in both oligodendrocyte and astrocyte lineage cells; a synthetic peptide (PLP 215-232) exhibited a similar activity. Doseresponse curves of PLP and PLP peptide showed maximum activities at a concentration in the picomolar range, which decreased at higher concentrations. These observations demonstrate that a secreted PLP gene product exerts biological activity at a premyelinating stage before the major induction of the gene.

Key words: oligodendrocyte development; myelin proteolipid protein; DM20; differentiation factor; myelin; cell culture sion may be related to the secretion of humoral factor(s) that influence maturation and survival of oligodendrocytes. Furthermore, a partial rescue of jimpy oligodendrocytes was observed when embryonic jimpy brain fragments were transplanted into brains expressing a wild-type PLP gene (Lachapelle et al., 1991). Finally, the number of oligodendrocytes present in mixed glial cell cultures containing conditioned media from cell lines expressing the PLP gene (G26 mouse oligodendroglioma, B104 rat neuroblastoma, and B16 mouse melanoma) (Ikenaka et al., 1992) was significantly higher than that of control cultures without conditioned media or those supplemented with conditioned medium from NIH3T3 fibroblasts, which do not produce DM20 (Nakao et al., 1995). However, when NIH3T3 cells were modified to produce PLP or DM20, the cells secreted a factor [which is neither platelet-derived growth factor (PDGF) nor basic fibroblast growth factor (bFGF)] that increased the number of oligodendrocytes (Nakao et al., 1995). Taken together, these findings indicated that the expression of the PLP gene is sufficient for, and directly associated with, the secretion of a factor that influences oligodendrocyte development.

In the present study we demonstrate that a portion of PLP/ DM20 is directly secreted into the medium in vitro and displays biological activity against oligodendrocytes and astrocytes. Furthermore, a synthetic peptide corresponding to PLP 215-232 was able to reproduce the activity found in the conditioned media of PLP/DM20-producing cells. A biological effect of the PLP fragment was observed at extremely low concentrations ( $0.3 \mathrm{pM})$. Therefore, although PLP gene expression in embryonic brain is very low and can only be detected by RT-PCR or in situ hybridization, the possibility of a function for PLP/DM20 in the embryonic brain is proposed.

\section{MATERIALS AND METHODS}

Materials. ICR mice were obtained from Nihon SLC (Hamamatsu, Japan). Monoclonal anti-galactocerebroside antibody (O1, mouse $\operatorname{IgM}$ ) (Sommer and Schachner, 1981; Bansal et al., 1989) was a gift from Dr. 
Steve Pfeiffer (University of Connecticut, Storrs, CT). The peptides of PLP (residues 209-217, 215-232, and 264-276) were synthesized in the laboratory of Dr. Richard Laursen (Department of Chemistry, Boston University, Boston, MA) or obtained from Peptide Institute (Osaka, Japan).

Cell line cultures and conditioned media. Previously we established PLP- or DM20-producing NIH3T3 fibroblast cell lines using retrovirus (Nakao et al., 1995). PLP- or DM20-producing NIH3T3 cells were maintained in DMEM (Life Technologies, Gaithersburg, MD) with $10 \%$ fetal bovine serum (FBS; ICN Biochemicals, Costa Mesa, CA; lot 10508092). After $48 \mathrm{hr}$, medium was changed to serum-free chemically defined N4 medium (Bottenstein et al., 1988). G26 mouse oligodendroglioma (Sundarraj et al., 1975), B104 rat neuroblastoma (Schubert et al., 1975), and B16 mouse melanoma (Hu and Lesney, 1964) cells were maintained in a 1:1 mixture of DMEM and Ham's F-12 medium supplemented with $10 \%$ FBS. Cells were plated at $60 \%$ confluence; after $12 \mathrm{hr}$ medium was changed to serum-free chemically defined N4 medium. After a further $24 \mathrm{hr}, 1 \mu \mathrm{g} / \mathrm{ml}$ phenylmethylsulfonyl fluoride was added to the conditioned media from the cell lines. Cell debris was removed by brief centrifugation. The supernatants were further concentrated as described previously (Nakao et al., 1995). The samples were aliquoted and stored at $-70^{\circ} \mathrm{C}$. Protein concentration was determined using a Bio-Rad (Hercules, CA) protein assay with bovine serum albumin as a standard.

Preparation of purified PLP and PLP peptides. PLP was solubilized in a detergent [first in Triton X-100 and finally in 3-[(3-cholamidopropyl) dimethylammonio]-1-propanesulfonic acid (CHAPS)] and purified from mouse cerebella as described previously (Yamaguchi et al., 1996), and gave a single band on SDS-PAGE stained with a Silver Stain II kit (Wako Chemicals, Neuss, Germany). Protein concentration was estimated by Bio-Rad protein assay and confirmed by amino acid analysis after gas phase acid hydrolysis.

Lyophilized PLP peptides were dissolved in $15 \mathrm{~mm} \mathrm{HCl}$. Stock solutions $(10 \mathrm{mg} / \mathrm{ml})$ were stored at $-80^{\circ} \mathrm{C}$. For the experiment they were diluted with O3/N4 defined medium (see Primary mouse glial cell culture) and added to the glial cell cultures.

Primary mouse glial cell culture. Neuroglial cells were isolated from embryonic day 17 (E17) cerebral hemispheres of ICR mice. Dissociated mixed glial cell cultures were prepared as described before (Nakao et al., 1995). The dissected tissue was cut into pieces with scalpels and shaken for $15-20 \mathrm{~min}$ at $37^{\circ} \mathrm{C}$ in $\mathrm{Ca}^{2+}$ - and $\mathrm{Mg}^{2+}$-free PBS containing $0.25 \%$ bovine pancreatic trypsin (Difco, Detroit, MI), 0.5\% glucose (Sigma, St. Louis, MO), and $50 \mu \mathrm{g} / \mathrm{ml}$ DNase I (Boehringer Mannheim, Indianapolis, IN). After trypsinization, the cells were dissociated in DMEM (Life Technologies) containing 10\% FBS (Life Technologies) by gentle pipetting through a flame-polished Pasteur pipette. The cells were then plated on polyethylenimine-coated plastic disks ( $9 \mathrm{~mm}$ in diameter; Aclar) at a density of $3 \times 10^{5} / \mathrm{cm}^{2}$ in $10 \mathrm{~cm}$ Petri dishes. After the cells attached to the disks, $10 \mathrm{ml}$ of $10 \%$ FBS-containing DMEM were added to the dish. After $3 \mathrm{~d}$ in vitro (3 DIV) the disks were randomly transferred into $3.5 \mathrm{~cm}$ dishes (six disks per dish) containing $3 \mathrm{ml}$ of a serum-free chemically defined medium (2:1 mixture of N4/O3 media; Bottenstein et al., 1988), allowed to grow for a further $4 \mathrm{~d}$, and processed for immunostaining. Conditioned media from NIH3T3 cells engineered to produce PLP/ DM20, purified PLP/DM20, or synthetic peptides were added together with the chemically defined medium at E17 + 3 DIV. The control disks, either untreated or treated with solvent, were processed in parallel with experimental disks. We always observed some difference in basal numbers of galactocerebroside (GalC)-positive cells in primary mixed glial cell cultures after 7 DIV, but it did not alter the effect of PLP/DM20 on the GalC-positive cells.

We have routinely used primary cultures prepared from E17 mouse cerebral hemispheres, began treatment after 3 DIV corresponding to postnatal day 1 (P1), and counted GalC-positive cells after a further 4 DIV corresponding to P5. In some cases we prepared the cells from E17 and P2 mouse cerebral hemispheres simultaneously and processed them in parallel. Thus, we could compare effects of purified PLP/DM20 or the PLP peptides in the two cultures: one corresponding to P5 and another to $\mathrm{P} 9$.

Immunostaining. To assess the number of GalC-positive cells, plastic disks with live cells were incubated with monoclonal mouse anti-GalC antibody, $\mathrm{O} 1$, for $30 \mathrm{~min}$ at $37^{\circ} \mathrm{C}$. The disks were washed three times and fixed with $4 \%$ paraformaldehyde for $10 \mathrm{~min}$. The cell cultures were treated with fluorescein-conjugated goat anti-mouse IgM (1:200; Cappel, West Chester, PA) for $1 \mathrm{hr}$ at room temperature and examined and counted under an Olympus Optical (Tokyo, Japan) Vanox-S fluorescence microscope.

Preparation of the AA3 and AH7-2a antibodies, neutralization, and immunoabsorbtion experiments. Production of AA3 and AH7-2a monoclonal antibodies and hybridoma was described previously (Yamamura et al., 1991). The AA3 and AH7-2a antibodies were purified using a general ammonium sulfate precipitation method.

In neutralization experiments, anti-PLP monoclonal antibodies (AA3 and AH7-2a) were incubated with the samples (purified PLP/DM20 or supernatants from PLP/DM20-transformed cells) at $4^{\circ} \mathrm{C}$ for $60 \mathrm{~min}$ and added to the serum-free chemically defined medium. During the next $4 \mathrm{~d}$ the medium was not changed. The cells were immunostained $4 \mathrm{~d}$ after addition of the samples, corresponding to P5, and the total number of GalC-positive cells was counted at least on the three different disks per each point.

In immunoabsorption of samples with protein G-Sepharose, $1 \mathrm{mg}$ each of the IgG fractions was dissolved in binding buffer $(0.5 \mathrm{M}$ acetate buffer, $\mathrm{pH} 4.6$, containing $1.5 \mathrm{M} \mathrm{NaCl})$ and added to $200 \mu \mathrm{l}$ of protein G-Sepharose suspension (Sigma). The solutions were incubated for $18 \mathrm{hr}$ at room temperature on a rotator. After the incubation, each solution was poured into a column and then washed with a serum-free chemically defined medium (see Primary mouse glial cell culture). The washed gel was transferred into a tube and incubated with $30 \mu \mathrm{g} / \mathrm{ml}$ enriched supernatant from DM20-producing NIH3T3 cells for $18 \mathrm{hr}$ at $4^{\circ} \mathrm{C}$ on a rotator. After incubation samples were filtered through a $0.22 \mu \mathrm{m}$ filter and added to the primary mouse mixed glial cell culture.

Bromodeoxyuridine immunohistochemistry on mixed glial cell culture. To study the growth of oligodendrocyte progenitors in serum-free culture conditions, bromodeoxyuridine (BrdU) labeling reagent (Amersham, Arlington Heights, IL) was added 2 d after introducing samples into mixed glial cell culture (5 DIV). Cells were cultured in the presence of BrdU for $24 \mathrm{hr}$. After BrdU treatment, the cell cultures were washed with defined medium and transferred to a BrdU-free medium for 1 more day (until 7 DIV). Double labeling immunocytochemistry was performed using anti-BrdU and anti-GalC or anti-GFAP antibodies.

Living cells on the disks were incubated with $\mathrm{O} 1$ antibody, followed by rhodamine-conjugated goat anti-mouse IgM ( $\mu$ chain specific, 1:50; Cappel). The disks were washed three times with PBS $\left(\mathrm{Mg}^{2+}\right.$ and $\mathrm{Ca}^{2+}$ free), fixed with acid-ethanol for $10 \mathrm{~min}$, and then treated with DNase I and anti-5-bromo-2'-deoxyuridine antibody (Amersham) for $1 \mathrm{hr}$ at room temperature. Incorporated BrdU was detected by immunofluorescence using FITC-conjugated goat anti-mouse IgG (Vector Laboratories, Burlingame, CA).

Cell count. We counted the total number of GalC-positive cells on at least three different disks per each point. The number of $\mathrm{GalC}$-positive cells in three experimental and three control disks was compared with an unpaired one-tailed $t$ test $(p<0.05)$ using Microsoft (Redmond, WA) Excel software from Microsoft Office 98. An average of three disks was counted per each group. The number of GalC-positive cells from the three control disks was taken as $100 \%$. Error bars represent SDs. Each experiment was repeated at least three times, but here we present only one representative set of data for each experiment. Cell count was blind; i.e., the person counted the cell number without being informed of the nature of experiments.

\section{RESULTS}

\section{The activities of enriched supernatants from PLP/ DM20-producing NIH3T3 fibroblast cells were completely inhibited by anti-PLP antibody}

When NIH3T3 fibroblasts were engineered to produce either PLP or DM20 mRNA, these cells began to secrete a factor that was able to increase the number of GalC-positive cells in primary glial cell cultures (Nakao et al., 1995). To examine the possibility that the expression of PLP/DM20 results in the secretion of PLP and DM20 themselves or their fragments, a monoclonal antibody to PLP/DM20 (AA3) recognizing the C terminus of PLP/DM20 (Fig. 1) was added to the cultures. Incubation of the supernatants from the PLP/DM20-producing fibroblasts with $10 \mu \mathrm{g} / \mathrm{ml}$ AA3 antibody for $60 \mathrm{~min}$ before its addition to the chemically defined medium completely inhibited activity of the supernatants (Fig. 2). Antibody alone did not affect the appearance of GalC-positive 


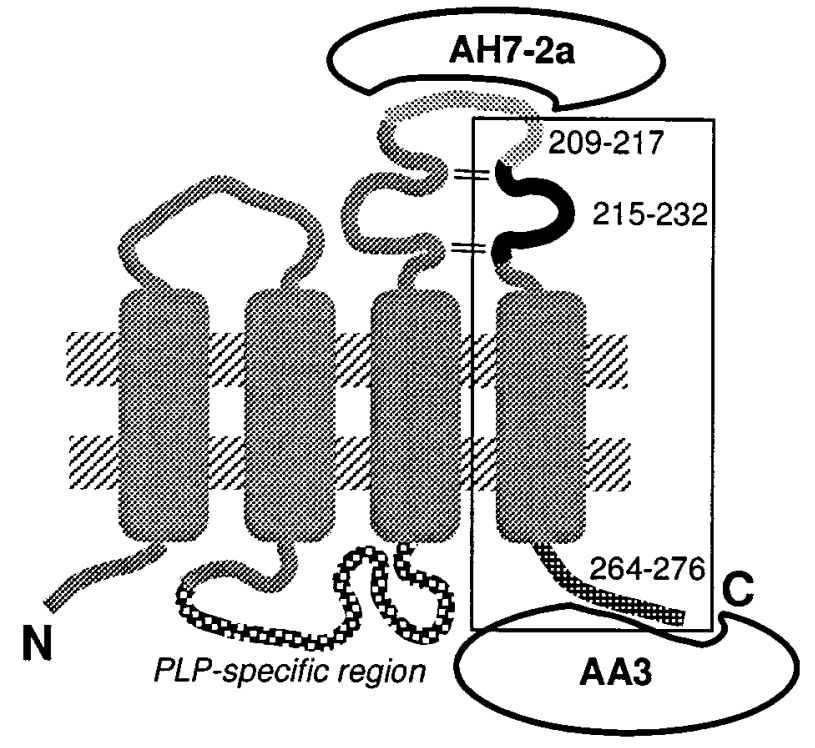

Figure 1. Current model of the topology of PLP in the plasma membrane of mature oligodendrocytes (Weimbs and Stoffel, 1992). However, nothing is known about structure of PLP during oligodendrocyte development. Positions of synthetic PLP peptides and antibody-binding sites are indicated. The $\mathrm{C}$-terminal portion of the molecule secreted into the medium is marked by a square.

cells (Fig. 2, bar 2). These findings suggest that PLP/DM20 itself or a fragment containing the $\mathrm{C}$-terminal region is released into the culture medium and increases the number of oligodendrocytes.

\section{Purified PLP and DM20 increase the number of oligodendrocytes}

To address more directly whether PLP or DM20 increases the number of oligodendrocytes, highly purified PLP isolated from a P2/P3 membrane fraction of ddY mouse cerebella (Yamaguchi et al., 1996) was added to mixed glial cell cultures in place of conditioned media (during the purification procedure PLP was separated from DM20). After $4 \mathrm{~d}$ in vitro in the presence of purified PLP, the number of GalC-positive cells was increased twofold in a dose-dependent manner up to $10 \mathrm{pg} / \mathrm{ml}$ (Fig. 3A), whereas higher concentrations of protein reduced the activity. The detergent (CHAPS) used to solubilize PLP had no effect on the number of GalC-positive cells at the concentration used (data not shown). The activity of the purified PLP at $10 \mathrm{pg} / \mathrm{ml}$ was completely inhibited by incubation with $1.25-2.5 \mu \mathrm{g} / \mathrm{ml}$ AA3 before addition to the cell culture (Fig. $3 B$ ). AA3 antibody alone did not influence the number (Fig. $3 B$ ) or morphology (data not shown) of oligodendrocytes.

The increase in the number of GalC-positive oligodendrocytes in response to purified PLP was less prominent at concentrations $>100 \mathrm{pg} / \mathrm{ml}$ (Fig. $3 A, B$, bar 5). To eliminate the possibility that this decreased activity was mediated by inhibitory factors contaminating the preparations, primary glial cell cultures were treated with $10^{4} \mathrm{pg} / \mathrm{ml}$ purified PLP together with the AA3 antibody $(2.5 \mu \mathrm{g} / \mathrm{ml})$. The treatment resulted in an increase of GalC-positive cell number (Fig. 3B, bar 6, C). Therefore, the reduced activity of purified PLP at high concentrations was not mediated by the contamination with inhibitory factors, but rather by the properties of PLP itself.

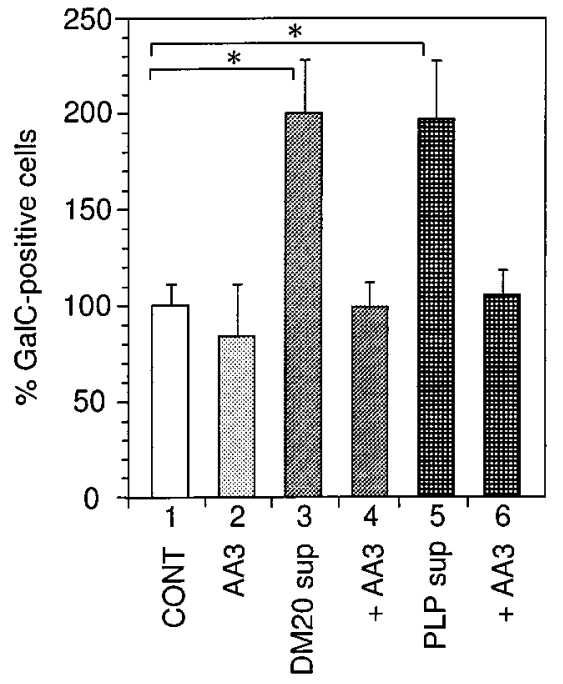

Figure 2. Effect of anti-PLP monoclonal antibody (AA3) on the activity of PLP- or DM20-enriched supernatants (sup). Conditioned media from PLP or DM20-producing cells were enriched as described previously (Nakao et al., 1995). These enriched samples $(30 \mu \mathrm{g} / \mathrm{ml}$ total protein concentration) were preincubated with AA3 antibody at $4^{\circ} \mathrm{C}$ for $60 \mathrm{~min}$ and added to the chemically defined medium. The mixture was applied to cell culture and kept for $4 \mathrm{~d}$ without medium change, and then the cells were fixed and immunostained for $\mathrm{O} 1$ antibody recognizing GalC. Bar 1, Enriched conditioned media from NIH3T3 cells containing $\mathrm{pDL}^{+}$retrovirus vector without cDNA inserts (CONT, control); bar 2, $10 \mu \mathrm{g} / \mathrm{ml}$ AA3 antibody; bar 3, enriched conditioned media from DM20-producing NIH3T3 cells; bar 4, enriched conditioned media from DM20-producing NIH3T3 cells together with $10 \mu \mathrm{g} / \mathrm{ml}$ AA3 antibody; bar 5, enriched conditioned media from PLP-producing NIH3T3 cells; bar 6, enriched conditioned media from PLP-producing NIH3T3 cells together with 10 $\mu \mathrm{g} / \mathrm{ml}$ AA3 antibody. Cells were immunostained for $\mathrm{O} 1$ antibody recognizing GalC. The total number of GalC-positive cells was counted on three different disks. Mean values of three control disks (69.6 cells per disk) had been taken as 100 percent. Error bars indicate SD. *Significant difference between the two groups was calculated with an unpaired one-tailed $t$ test $(p<0.05)$.

\section{The activity increasing the number of oligodendrocytes present in established neural cell lines is also mediated by PLP/DM20}

We have previously shown that DM20 mRNA is produced in many neuronal cell lines (Ikenaka et al., 1992), and that a correlation can be found between PLP gene expression by the cell lines and the potency of the supernatants for increasing the number of oligodendrocytes (Nakao et al., 1995). To investigate the possible involvement of PLP/DM20 as an active element in these supernatants, AA3 monoclonal antibody $(10 \mu \mathrm{g} / \mathrm{ml})$ was added to the assay system. The number of GalC-positive cells was examined after incubation of the mixed glial cultures for $4 \mathrm{~d}$ in $\mathrm{O} 3$ defined medium containing 33\% supernatants from G26, B104, and B16 cell lines (Fig. 4). Supernatants from G26, B104, and B16 cell lines increased the number of GalC-positive cells sixfold, threefold, and twofold of the control level, respectively (Fig. 4, bars 3, 5, 7). Pretreatment with AA3 antibody significantly inhibited this activity in the supernatants (Fig. 4, bars 4, 6, 8). These results suggest that the expression of the PLP gene in established neuronal cell lines resulted in secretion of PLP/DM20 or its fragment into the medium, which in turn, could increase the number of oligodendrocytes in culture. 
A

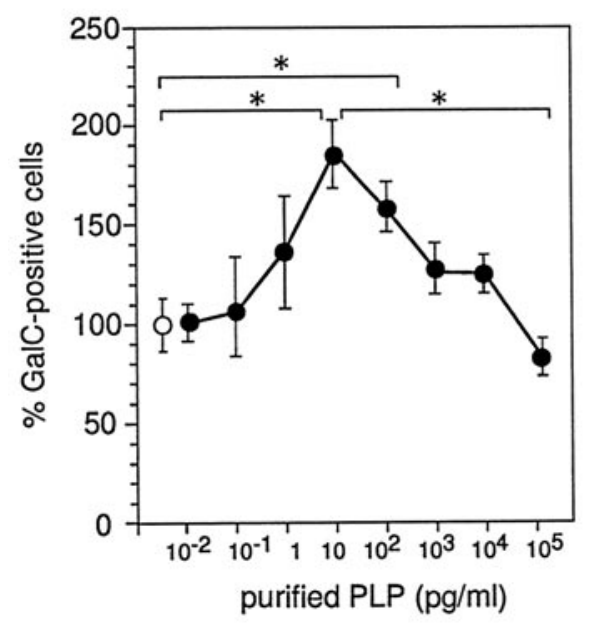

Figure 3. Effect of purified PLP and partially purified DM20 on the number of oligodendrocytes. $A$, Purified PLP and the number of GalC-positive cells was counted. Open circle, Control culture without PLP. Cells were immunostained for $\mathrm{O} 1$ antibody recognizing GalC. The total number of GalCpositive cells was counted on three different disks. Mean value of three control disks (77.6 cells per disk) had been taken as $100 \%$. Error bars indicate SD. * Significant difference between the two groups was calculated with an unpaired one-tailed $t$ test $(p<0.05)$. B, Effect of purified PLP and monoclonal antibody AA3 on the number of GalC-positive cells. Mixed glial cell cultures were grown in the presence of purified PLP or PLP preincubated with AA3 antibody for $4 \mathrm{~d}$, and then the cultures were fixed, and the number of $\mathrm{GalC}$-positive cells were counted. Mean values of three control disks (61.1 cells per disk) had been taken as $100 \%$. Error bars indicate SD. Bar 1, Defined medium (CONT); bar 2, $1.25 \mu \mathrm{g} / \mathrm{ml}$ AA3; bar 3, $10 \mathrm{pg} / \mathrm{ml}$ purified PLP; bar 4, $10 \mathrm{pg} / \mathrm{ml}$ purified PLP plus $1.25 \mu \mathrm{g} / \mathrm{ml}$ AA3; bar $5,10^{4}$ $\mathrm{pg} / \mathrm{ml}$ purified PLP; bar $6,10^{4} \mathrm{pg} / \mathrm{ml}$ purified PLP plus $2.5 \mu \mathrm{g} / \mathrm{ml}$ AA3. $C$, Typical photographs of immunocytochemical staining of cultured oligodendrocytes using monoclonal O1 antibody (anti-GalC antibody). C1, Defined medium; $C 2,10 \mathrm{pg} / \mathrm{ml}$ purified PLP; C3, $10^{4} \mathrm{pg} / \mathrm{ml}$ purified PLP; C4, $10 \mathrm{pg} / \mathrm{ml}$ purified PLP plus $2.5 \mu \mathrm{g} / \mathrm{ml}$ AA $3 ; C 5$, $10^{4} \mathrm{pg} / \mathrm{ml}$ purified PLP plus $2.5 \mu \mathrm{g} / \mathrm{ml}$ AA3. Scale bar, $100 \mu \mathrm{m}$.

C

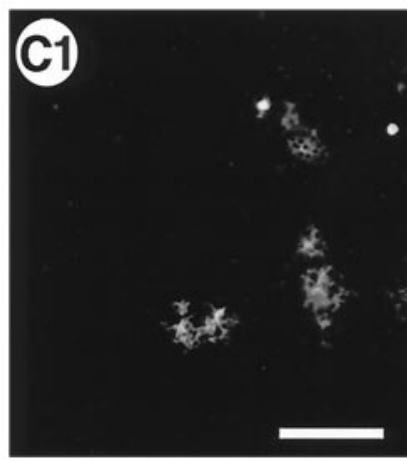

B
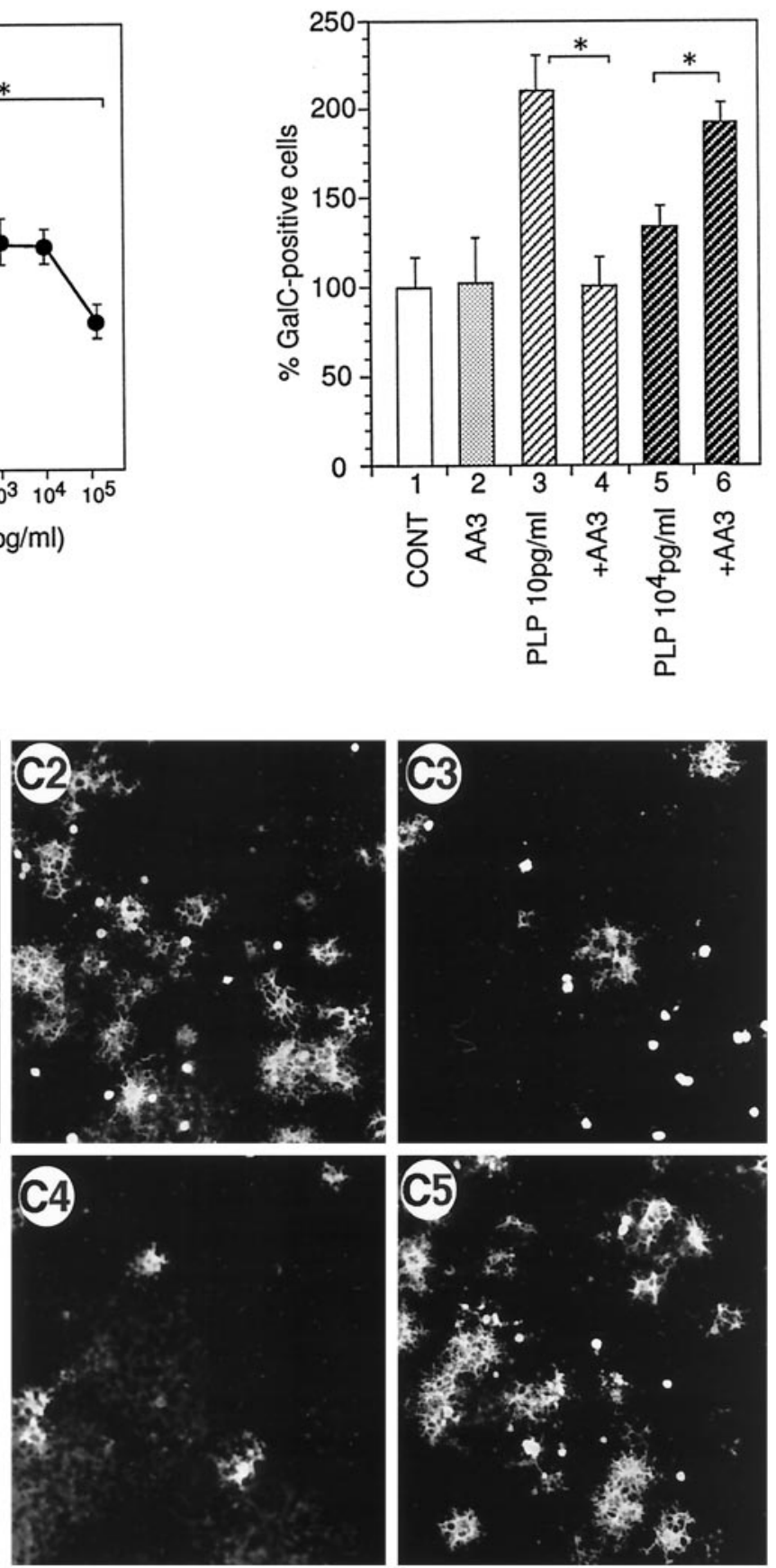

\section{Enriched supernatants from NIH3T3 cells producing PLP or DM20 increased the number of BrdU-labeled oligodendrocytes and astrocytes}

To investigate whether the factor increases the proliferation rate of progenitor cells, glial cultures were treated with enriched supernatants from PLP- or DM20-producing NIH3T3 cells and exposed to BrdU for $24 \mathrm{hr}$. As a control we used those from NIH3T3 cells harboring retroviral vector without cDNA inserts. The enriched supernatants from both PLP- and DM20-producing cells increased the number of O1-positive cells incorporating BrdU as well as the total number of O1-positive cells (twofold increase; Table 1). Surprisingly, the total number of BrdUlabeled and GFAP-positive cells (the major cell population rep- resented by astrocytes) also increased approximately two fold. This indicates that the presence of the PLP/DM20 or its fragment affects proliferation of various glial cell types.

\section{Structural analysis of the PLP gene products secreted into the culture medium}

Purified PLP increased the number of oligodendrocytes (Fig. $3 A$ ). To examine whether DM20 can cause a similar effect, DM20 partially purified and separated from PLP by column chromatography (Yamaguchi et al., 1996) was added to mixed glial cell cultures. The DM20 fraction significantly increased the number of oligodendrocytes (Fig. 5, bar 6). A purified proteolipid mixture containing PLP and DM20 isolated from adult ICR mouse brain 


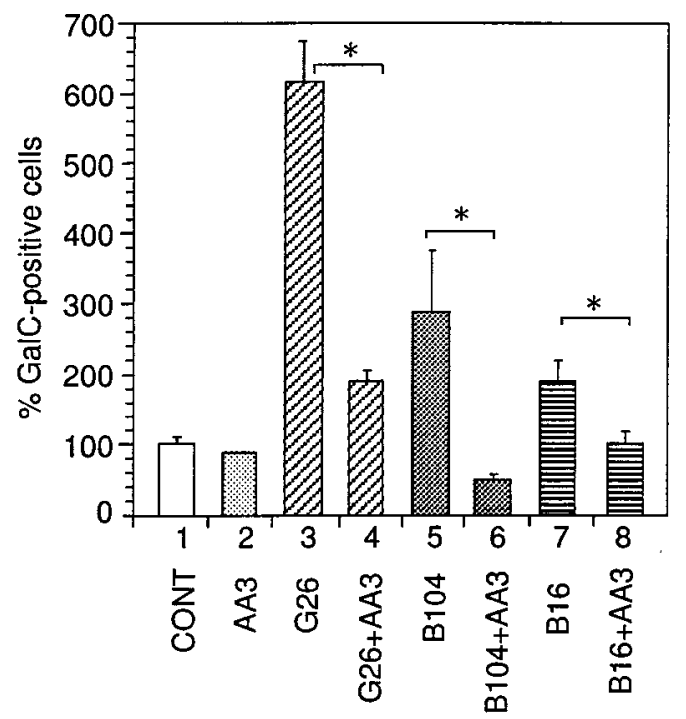

Figure 4. Effect of the conditioned media (CM) obtained from G26, B104, and B16 cell lines and AA3 antibody on the number of GalCpositive cells. Mixed glial cells were cultured in a mixture of $\mathrm{CM}$ and chemically defined medium $\mathrm{O} 3 / \mathrm{N} 4$ in a ratio of $1: 2$. AA3 antibody was incubated with $\mathrm{CM}$ for $60 \mathrm{~min}$ at $4^{\circ} \mathrm{C}$ before addition to the defined medium, and the cells were cultured in the mixture for $4 \mathrm{~d}$ without medium change. Mean value of three control disks $\left(51.6 \mathrm{cells} / \mathrm{mm}^{2}\right)$ had been taken as $100 \%$. Error bars indicate SD. *Significant difference between the two groups was calculated with an unpaired one-tailed $t$ test $(p<0.05)$. Bar 1, Chemically defined medium (CONT); bar 2, 10 $\mu \mathrm{g} / \mathrm{ml}$ AA3; bar 3, CM from G26 cells; bar 4, CM from G26 cells plus $10 \mu \mathrm{g} / \mathrm{ml}$ AA3; bar 5, CM from B104 cells; bar 6, CM from B104 cells plus $10 \mu \mathrm{g} / \mathrm{ml}$ AA3; bar 7, CM from B16 cells; bar 8, CM from B16 cells plus $10 \mu \mathrm{g} / \mathrm{ml} \mathrm{AA3}$.

by organic solvent extraction (chloroform-methanol and etherethanol) (Monreal, 1975) also increased the number of oligodendrocytes (data not shown). These results demonstrate that both PLP and DM20 affect the oligodendrocyte maturation and survival in a similar manner, and that correct folding of PLP/DM20 may not be necessary for this activity.

To gain further insight into the structure of the secreted PLP gene product, we studied whether the activity could be blocked by AH7-2a, a monoclonal antibody recognizing PLP 209-217 (Fig. 1). Pretreatment of the enriched supernatants from PLP/DM20producing NIH3T3 cells with AH7-2a monoclonal antibody for $60 \mathrm{~min}$ before its addition to the cell culture had no effect on its ability to increase the number of oligodendrocytes (data not shown), whereas pretreatment with AA3 antibody completely inhibited it (Fig. 2). This result suggests that the secreted PLP gene product contains the $\mathrm{C}$ terminus of PLP/DM20 but not the epitope 209-217 of PLP. To address this issue more directly, immunoabsorption experiments were performed. The enriched supernatant from DM20-producing cells was incubated with protein G-Sepharose coupled with AA3 or AH7-2a antibodies. Eluted samples were collected, and their activity was checked. The activity of the enriched supernatant from DM20-producing cells was completely absorbed by protein G-AA3 (Fig. 5, bar 5) but not by protein G-AH7-2a (Fig. 5, bar 4) or protein G-normal rat IgG (Fig. 5, bar 3). However, when $100 \mathrm{pg} / \mathrm{ml}$ partially purified DM20 was added to the protein G-Sepharose coupled with AA3 or AH7-2a, activity to increase the number of GalC-positive cells was absorbed with both AA3 (Fig. 5, bar 8) and the AH7-2aprotein G column (Fig. 5, bar 7) but not with protein
G-Sepharose coupled with normal rat IgG (Fig. 5, bar 6). These results show that AH7-2a antibody can absorb DM20, but the epitope recognized by AH7-2a is absent in the secreted form of the PLP gene product.

\section{A synthetic peptide corresponding to a portion of PLP/ DM20 increases the number of oligodendrocytes}

To further identify and characterize the active region of PLP/ DM20, we used three PLP peptides, 209-217, 215-232, and 264-276. The residues 209-217 and 264-276 (C-terminal sequence) are specifically recognized by AH7-2a and AA3 antibodies, respectively (Fig. 1). Only the PLP peptide 215-232 increased the number of oligodendrocytes in the mixed glial cell culture (Fig. 6A). The dose-response curve of PLP peptide (215-232) shows that this fragment had reduced activity at high concentrations (Fig. 6B), similar to that observed for purified PLP (Fig. $3 A$ ). The solvent used to solubilize peptides had no effect (data not shown). Thus, it is most likely that the active region includes residues $215-232$.

During the experiment we found that PLP peptide 215-232 was very unstable at neutral $\mathrm{pH}$, which was the reason we dissolved this peptide in $15 \mathrm{~mm} \mathrm{HCl}$. We also synthesized a peptide in which two cysteine residues had been substituted to serine. This peptide was much more stable and showed a dose-response curve similar to that of PLP peptide 215-232 (Fig. 6B).

\section{Addition of partially purified PLP or PLP peptide to the cell cultures prepared from P2 mouse brain did not affect the number of oligodendrocytes}

Both PLP and PLP peptide showed a similar bell-shaped doseresponse curve (Figs. 3, 6). Hence, when the PLP gene expression is robustly induced a few days after birth, the culture system we are using should eventually be saturated with the secreted PLP gene product. We have routinely used primary hemisphere cell cultures prepared from E17 mice and began treatment with the conditioned medium after $3 \mathrm{~d}$ in vitro, corresponding to P1. At this point there is still very little PLP gene expression and no detectable PLP protein (data not shown). However, only 3 d later PLP/DM20 mRNA will be abundant enough to be detected by RNA dot analysis (Okano et al., 1987). We thus cultured the cells from large hemispheres from E17 and P2 (4 d after E17) and asked whether the latter can respond to the exogenously added, partially purified PLP or PLP peptide. As shown in Figure 7, the number of GalC-positive cells in P2 cultures did not increase with the addition of PLP or PLP peptide. Additional experiments had shown that by the time of addition of exogenous PLP the cells already contained detectable amount of endogenous protein (data not shown). Thus, the biological activity of secreted PLP gene product can be exerted only when the PLP gene expression level is very low as in an embryonic brain.

\section{DISCUSSION}

\section{A premyelinating function of the PLP gene product}

PLP/DM20 mRNA-positive cells appear at approximately E11 in several restricted areas of the brain and then subsequently spread throughout the brain (Timsit et al., 1992, 1995). It is still a matter of debate whether these cells are oligodendrocyte progenitors and whether the spreading involves active cell migration or a wave of differentiation (Gonye et al., 1994; Hardy and Friedrich, 1996). One important clue to answering these questions would be to understand the function of the early expressed PLP gene product. In this study we have shown that the PLP gene product is secreted 
Table 1. Supernatants from PLP/DM-20-producing cells promote gliogenesis in vitro

\begin{tabular}{llccc} 
& $\begin{array}{l}\text { Total } 1^{+} \\
\text {cells }\left(\mathrm{cm}^{2}\right)\end{array}$ & $\begin{array}{l}\mathrm{BrdU}^{+} / \mathrm{O}^{+} \\
\text {cells }\left(\mathrm{cm}^{2}\right)\end{array}$ & $\begin{array}{l}\text { Total BrdU } \\
\text { cells }\left(\mathrm{mm}^{2}\right)\end{array}$ & $\begin{array}{c}\text { Total GFAP } \\
\text { cells }\left(\mathrm{mm}^{2}\right)\end{array}$ \\
\hline Control & $103.8 \pm 7.8$ & $8.9 \pm 1.9$ & $89 \pm 18$ & $573 \pm 54$ \\
DM-20 sup & $212.3 \pm 10.5^{*}$ & $17.8 \pm 0.7^{*}$ & $180 \pm 26^{*}$ & $1050 \pm 159^{*}$ \\
PLP sup & $219.1 \pm 14.1^{*}$ & $28.3 \pm 5.8^{*}$ & $204 \pm 37^{*}$ & $1000 \pm 134^{*}$
\end{tabular}

Cultures (5 DIV) were incubated with BrdU for $24 \mathrm{hr}$ and then cultured for $1 \mathrm{~d}$ before fixation followed by double immunostaining for $\mathrm{O} 1$ and anti-BrdU or GFAP and anti-BrdU antibodies. The total number of double-positive cells was counted in three different coverslips. The total number of $\mathrm{BrdU}^{+}$and $\mathrm{GFAP}^{+}$cells was extrapolated from the cell number in five fields at $20 \times$ magnification obtained from three different coverslips. Mean value $( \pm$ SD) from triplicate experiments is shown. sup, Supernatant.

${ }^{*} p<0.05$.

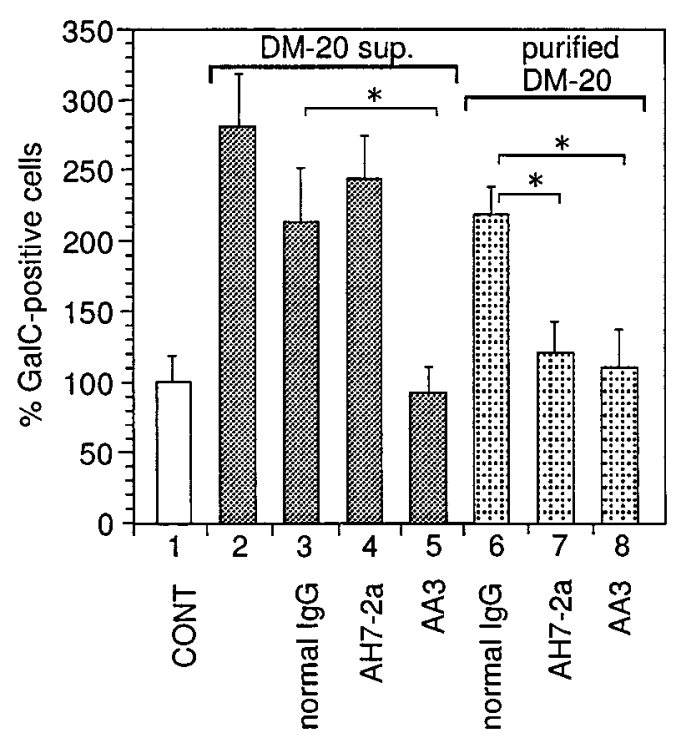

Figure 5. Enriched supernatant (sup.) from DM20-producing cells and partially purified DM20 were incubated with protein G-Sepharose resin coupled with AH7-2a-IgG, AA3-IgG, or normal rat IgG. The resins were poured into columns, and eluted fractions were collected and added to the primary cell cultures; the number of GalC-positive cells has been counted as described in Materials and Methods. Mean value of three control disks (72.7 cells per disk) had been taken as $100 \%$. Error bars indicate SD. *Significant difference between the two groups was calculated with an unpaired one-tailed $t$ test $(p<0.05)$. Bar $1,30 \mu \mathrm{g} / \mathrm{ml}$ (total protein content) enriched supernatant from NIH3T3 cells containing $\mathrm{pDL}^{+}$ retrovirus vector without cDNA inserts; bar $2,30 \mu \mathrm{g} / \mathrm{ml}$ enriched supernatant from DM20-producing NIH3T3 cells; bar 3, $30 \mu \mathrm{g} / \mathrm{ml}$ fraction eluted from resins coupled with normal rat IgG loaded with enriched supernatant from DM20-producing NIH3T3 cells; bar $4,30 \mu \mathrm{g} / \mathrm{ml}$ fraction eluted from resins coupled with $\mathrm{AH} 7-2 \mathrm{a} \mathrm{IgG}$ loaded with enriched supernatant from DM20-producing NIH3T3 cells; bar 5, $30 \mu \mathrm{g} / \mathrm{ml} \mathrm{frac-}$ tion eluted from resins coupled with AA3 IgG loaded with enriched supernatant from DM20-producing NIH3T3 cells; bar $6,100 \mathrm{pg} / \mathrm{ml}$ fraction eluted from resins coupled with normal rat IgG loaded with partially purified DM20; bar 7, $100 \mathrm{pg} / \mathrm{ml}$ fraction eluted from resins coupled with AH7-2a IgG loaded with partially purified DM20; bar $8,100 \mathrm{pg} / \mathrm{ml}$ of fraction eluted from resins coupled with AA3 IgG loaded with partially purified DM20.

into the medium and exerts biological effects at extremely low concentrations $(10 \mathrm{pg} / \mathrm{ml}, 0.3 \mathrm{pm})$. It increases the number of both GalC- and GFAP-positive cells, along with an increase in BrdU incorporation by these cells (Table 1). The fact that the secreted PLP gene product also acts on astrocytes provides a possible explanation for the abnormalities found in the astrocytes from the jimpy mutant mouse before the myelinating period (Skoff, 1976).

We do not know whether the secreted PLP gene product acts through a receptor-mediated pathway, or which cell type is directly stimulated. Before gliogenesis begins, the nervous system is composed mainly of neurons and neuroepithelial cells. Therefore, the target of the secreted PLP gene product at the early stage of neural development may not be glial cells but, rather, immature stem cells or neurons. Because axonal abnormalities are found in PLP mutants (Nixon, 1982), and many of the early DM20 mRNApositive cells are found in axon-rich regions (Timsit et al., 1995), it is intriguing to consider the possibility that the secreted PLP gene product may be a signal sent from DM20-producing cells to neurons.

In a transgenic mouse unable to synthesize PLP/DM20 (because of abnormal splicing), oligodendrocytes were present in a normal number (Boison and Stoffel, 1994; Boison et al., 1995). Normal number and development of oligodendrocytes were also observed in a PLP knock-out mouse (in which a portion of the PLP gene containing the translation initiation codon had been deleted) (Klugmann et al., 1997). It is known that compensation often occurs when an essential gene has been knocked out. Because DM20 has been shown to be part of a gene family (Kitagawa et al., 1993), another member of the family might compensate for the lack of the PLP/DM20 fragment. One candidate is M6b, which is also produced in oligodendrocytes and has high homology with PLP in the region corresponding to PLP 215-232 (12 amino acid residues of 18 identical). In most PLP mutants, including the jimpy mouse, oligodendrocytes degenerate. This may be caused by a "traffic jam" of mutant PLP gene products (Gow et al., 1994, 1997; Jung et al., 1996), which seem to exert a dominant effect over wild-type PLP gene products, as shown by the introduction of the wild-type PLP transgene into the jimpy mouse (Kagawa et al., 1994; Readhead et al., 1994, Schneider et al., 1995). Therefore, even if M6b were capable of functionally compensating for the absence of secreted PLP gene product in a PLP knock-out mouse, it may not be possible in many PLP mutants, potentially explaining the difference between the PLP knock-out mouse and mutants. We are currently studying the effect of M6b peptide on glial cells.

An important feature of this factor is that it loses biological activity at a high concentration (Fig. $3 A$ ) and does not affect the number of GalC-positive cells after the major induction of the PLP gene (Fig. 7). Because the expression level found in embryonic versus myelinating brain is so different, this self-shutting down may be necessary for normal development of the CNS. Otherwise oligodendrocytes will continuously increase in number.

\section{Possible structure of the secreted PLP gene product}

Anti-PDGF and anti-bFGF antibodies were unable to suppress the activity in the enriched supernatants from PLP/DM20- 
A

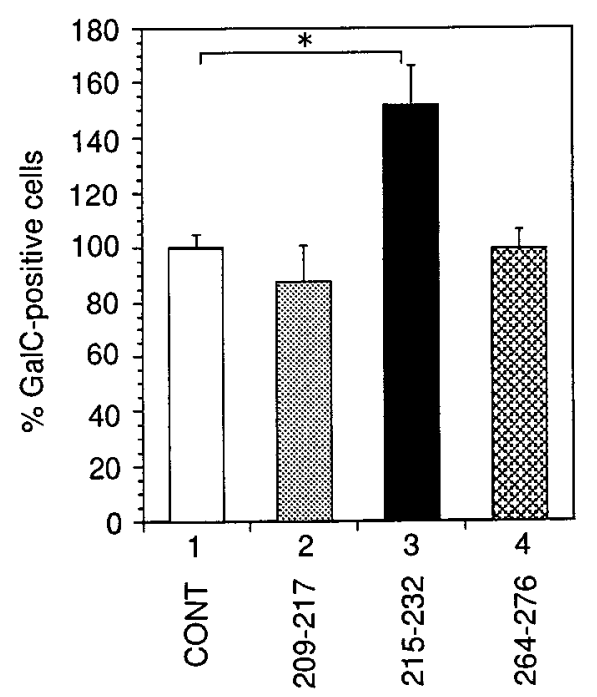

B

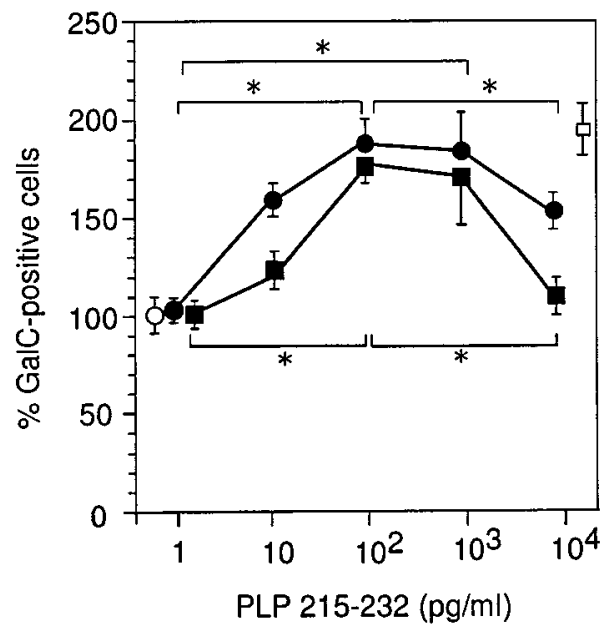

Figure 6. Ability of synthetic PLP peptides to increase the number of GalC-positive cells in the mixed glial cell culture. $A$, Cells were cultured in the presence of $10^{3} \mathrm{pg} / \mathrm{ml}$ various synthetic PLP peptides (209-217, 215-232, and 264-276) during $4 \mathrm{~d}$ before fixation. Positions of the peptides are indicated in Figure 1. The number of GalC-positive cells was counted. Mean value of three control disks $\left(4.5 \mathrm{cells} / \mathrm{mm}^{2}\right)$ cultured with the solvent had been taken as $100 \%$. Error bars indicate SD. *Significant difference between the two groups was calculated with an unpaired one-tailed $t$ test $(p<0.05)$. $B$, Different amounts of PLP peptide (215-232, closed circles) or serine-substituted PLP peptide (215-232, closed squares) were added to the glial cell cultures as described in Materials and Methods. The number of GalC-positive cells was counted. Open circle, Negative control (cells were cultured with a solvent); open square, positive control (cells were cultured in the presence of partially purified PLP [heparin fraction (Yamaguchi et al., 1996), 200 pg/ml total protein content]). Mean value of three negative control disks ( 42.2 cells per disk) had been taken as $100 \%$. Error bars indicate SD. *Significant difference between the two groups was calculated with an unpaired one-tailed $t$ test $(p<0.05)$.

producing NIH3T3 cells (Nakao et al., 1995). In contrast, the activity in the supernatants was clearly inhibited by AA3 (recognizing PLP residues 264-276) antibody (Fig. 2), whereas AH7-2a (recognizing PLP residues 209-217) antibody had no effect (Fig. 5). Thus, the PLP gene product secreted into the medium is not the whole molecule but a fragment containing the $\mathrm{C}$-terminal region of PLP/DM20 (although both PLP and DM20 exhibit a similar activity) (Figs. 3, 5). Addition of PLP 215-232 increased the number of oligodendrocytes in mixed glial cell culture (Figs. 6,7 ), and thus the active site of the secreted PLP fragment should lie within this portion of PLP/DM20. The secreted fragment should contain at least 60 amino acids between residues 215 and 264-276 (the C terminus of PLP/DM20 recognized by antibody AA3). Position of the secreted fragment is indicated in Figure 1 by a square.

There are several indications that correct folding of PLP/ DM20 may not be necessary for its function in oligodendrocyte proliferation. First, both PLP and DM20, when solubilized by the aid of detergent, increased the number of oligodendrocytes (Figs. 3, 5). Second, a proteolipid mixture, containing PLP and DM20, isolated from the brain by organic solvents exhibited a similar activity (data not shown). Third, synthetic peptide corresponding to residues 215-232 of the PLP could reproduce the effect of the whole PLP or its C terminus (Fig. 6); substitution of the two cysteine residues by serines did not disrupt the peptide activity (Fig. 6B).

Direct biochemical analysis of the secreted PLP gene product to determine its structure would be desirable. However, we have been unsuccessful in detecting a PLP/DM20 fragment in the supernatant after radiolabeling PLP/DM20-producing cells and immunoprecepitation with the AA3 antibody (Nakao et al., 1995). Thus, the fragment of PLP/DM20 present in supernatants

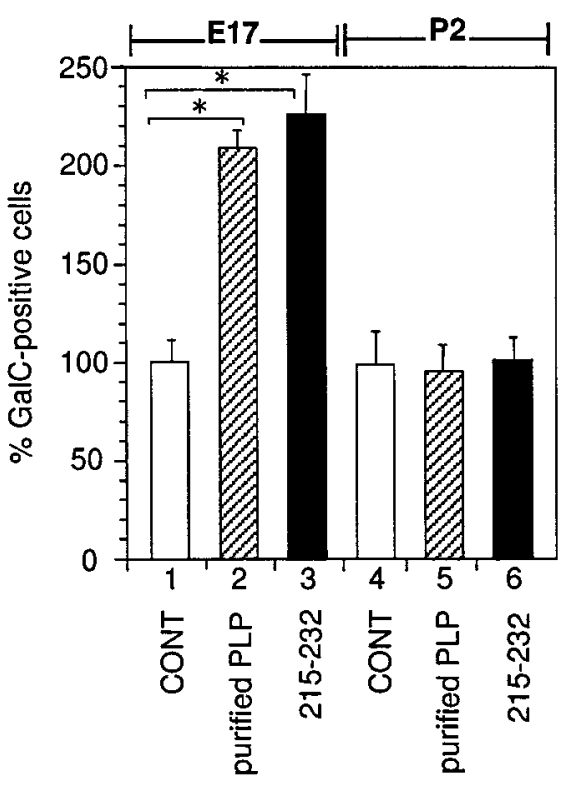

Figure 7. Effect of PLP or PLP peptide (251-232) on the mixed glial cultures prepared from different stages of development. Glial cells prepared from E17 and P2 were cultured with purified PLP or serinesubstituted PLP peptide (215-232) as described in Materials and Methods. Control (CONT) was cultured with the solvent only. Mean value of three negative control disks (171.9 cells per disk for E17 and 205.5 cells per disk for P2) had been taken as $100 \%$. Error bars indicate SD. *Significant difference between the two groups was calculated with an unpaired one-tailed $t$ test $(p<0.05)$. Bar 1, E17 + 7 DIV, solvent only; bar 2, E17 + 7 DIV, 10 pg/ml purified PLP; bar 3, E17 + 7 DIV, 100 $\mathrm{pg} / \mathrm{ml}$ serine-substituted PLP peptide (215-232); bar 4, P2 + 7 DIV, solvent only; bar 5, P2 + 7 DIV, $10 \mathrm{pg} / \mathrm{ml}$ purified PLP; bar 6, P2 + 7 DIV, $100 \mathrm{pg} / \mathrm{ml}$ serine-substituted PLP peptide (215-232). 
apparently exerts its activity at an extremely low concentration, consistent with the observation that purified PLP at $10 \mathrm{pg} / \mathrm{ml}(0.3$ $\mathrm{pm})$ gave a maximum increase in the number of GalC-positive cells.

\section{Factors contained in the B104 conditioned medium}

Hunter and Bottenstein $(1989,1991)$ previously reported that the B104 conditioned medium promotes growth of O-2A progenitors and subsequent increase in differentiated progeny. However, the B104 conditioned medium has not been fully characterized biochemically (Hunter and Bottenstein, 1991). Recently it was shown that the B104 cells produce and secrete PDGF-AA homodimer and transforming growth factor (TGF)- $\beta 1$ and $-\beta 2$, but the combination of PDGF and TGF- $\beta$ was not equivalent to the effect of B104 conditioned medium (Asakura et al., 1997), suggesting the presence of an unidentified factor. Because we have shown that the B104 cell line produces mRNA for DM20 (Ikenaka et al., 1992), and the biological activity of the B104 supernatant can be blocked by the addition of the AA3 antibody, one of the active components might be a secreted PLP gene product.

The number of oligodendrocytes was markedly increased with addition of B104 or G26 supernatant (up to sixfold), and this effect was also repressed by the addition of the AA3 antibody (Fig. 4). Neither purified PLP nor PLP peptide (215-232) by itself can increase the number of oligodendrocyte more than twofold to threefold. Thus, it is likely that the secreted PLP gene product coordinates with other factors to regulate gliogenesis.

Analysis of PLP mutant animals and humans (Pelizaeus Merzbacher disease) revealed many abnormalities that cannot be explained simply by the degeneration of oligodendrocytes, which are the predominant, if not the only, cell type expressing the PLP gene. Our finding that the PLP gene product can be secreted and exerts biological activity at an extremely low concentration suggests a need to reconsider the pathology of the PLP mutants. It should also lead to a further understanding of the mechanisms governing glial development.

\section{REFERENCES}

Asakura K, Hunter SF, Rodriguez M (1997) Effects of transforming growth factor- $\beta$ and platelet derived growth factor on oligodendrocyte precursors: insights gained from a neuronal cell line. J Neurochem 68:2281-2290.

Bansal R, Warrington AE, Gard AL, Ranscht B, Pfeiffer SE (1989) Multiple and novel specificities of monoclonal antibodies $\mathrm{O} 1, \mathrm{O} 4$, and $\mathrm{R}-\mathrm{mAb}$ used in the analysis of oligodendrocyte development. J Neurosci Res 4:548-557.

Bartlett WF, Knapp PE, Skoff RP (1988) Glial conditioned medium enables jimpy oligodendrocyte to express properties of normal oligodendrocytes: production of myelin antigens and membranes. Glia $1: 253-259$.

Boison D, Stoffel W (1994) Disruption of the compacted myelin sheath of axon of the central nervous system in proteolipid protein-deficient mice. Proc Natl Acad Sci USA 91:11709-11713.

Boison D, Büssow H, D'Urso D, Müller H-W, Stoffel W (1995) Adhesive properties of proteolipid protein are responsible for the compaction of CNS myelin sheaths. J Neurosci 15:5502-5513.

Bottenstein JE, Hunter SF, Seidel M (1988) CNS neuronal cell linederived factors regulated gliogenesis in neonatal rat brain cultures. J Neurosci Res 20:291-303.

Gonye GE, Warrington AE, DeVito JA, Pfeiffer SE (1994) Oligodendrocyte precursor quantitation and localization in perinatal brain using a retrospective bioassay. J Neurosci 14:5365-5372.

Gow A, Friedrich Jr VL, Lazzarini RA (1994) Many naturally occurring mutations of myelin proteolipid protein impair its intracellular transport. J Neurosci Res 37:574-583.

Gow A, Gragerov A, Gard A, Colman DR, Lazzarini RA (1997) Conservation of topology, but not conformation, of the proteolipid proteins of the myelin sheath. J Neurosci 17:181-189.
Hardy RJ, Friedrich VL (1996) Oligodendrocyte progenitors re generated throughout the embryonic mouse brain, but differentiated in restricted foci. Development 122:2059-2069.

Hu F, Lesney PF (1964) The isolation and cytology of two pigment cell strains from B16 mouse melanomas. Cancer Res 24:1634-1643.

Hudson LD, Nadon NL (1992) Amino acid substitutions in proteolipid protein that cause dysmyelination. In: Myelin: biology and chemistry (Martenson RE, ed), pp 677-702. Boca Raton, FL: CRC.

Hunter SF, Bottenstein JE (1989) Bipotential glial progenitors are targets of neuronal cell line-derived growth factors. Dev Brain Res 49:33-49.

Hunter SF, Bottenstein JE (1991) O-2A glial progenitors from mature brain respond to CNS neural cell line-derived growth factors. J Neurosci Res 28:574-582.

Ikenaka K, Kagawa T, Mikoshiba K (1992) Selective expression of DM20, an alternatively spliced myelin proteolipid protein gene product, in developing nervous system and in nonglial cells. J Neurochem 58:2248-2253.

Jung M, Sommer I, Schachner M, Nave K-A (1996) Monoclonal antibody O10 defines a conformationally sensitive cell-surface epitope of proteolipid protein (PLP): evidence that PLP misfolding underlies dysmyelination in mutant mice. J Neurosci 16:7920-7929.

Kagawa T, Ikenaka K, Inoue Y, Kuriyama S, Tsujii T, Nakao J, Nakajima K, Aruga J, Okano H, Mikoshiba K (1994) Glial cell degeneration and hypomyelination caused by overexpression of myelin proteolipid protein gene. Neuron 13:427-442.

Kitagawa K, Sinoway MP, Yang C, Gould RM, Colman DR (1993) A proteolipid protein gene family: expression in sharks and rays and possible evolution from an ancestral gene encoding a pore-forming polypeptide. Neuron 11:433-448.

Klugmann M, Schwab MH, Pühlhofer A, Schneider A, Zimmeremann F, Griffiths IR, Nave K-A (1997) Assembly of CNS myelin in the absence of proteolipid protein. Neuron 18:59-70.

Knapp PE (1996) Proteolipid protein: is it more than just a structural component of myelin? Dev Neurosci 18:297-308.

Knapp PE, Skoff RP, Benjamins JA, Studzinski DM (1992) Oligodendrocytes from hypomyelinated jimpy mice synthesize an altered PLP in vitro. Trans Am Soc Neurochem 23:134.

Lachapelle F, Lapie P, Campagnoni AT, Gumpel M (1991) Oligodendrocytes of jimpy phenotype can be partially restored by environmental factors in vivo. J Neurosci Res 29:235-243.

Levine SP, Wong D, Macklin WB (1990) Developmental expression of proteolipid protein and DM20 mRNAs and proteins in the rat brain. Dev Neurosci 12:235-250.

Mikoshiba K, Okano H, Tamura T, Ikenaka K (1991) Structure and function of myelin protein gene. Annu Rev Neurosci 14:201-217.

Monreal J (1975) Chromatographic fraction of brain white matter proteolipid. J Neurochem 24:539-541.

Moriguchi A, Ikenaka K, Furuichi T, Okano H, Iwasaki Y, Mikoshiba K (1987) The fifth exon of the myelin proteolipid protein-coding gene is not utilized in the brain of jimpy mutant mice. Gene 55:333-337.

Nakao J, Yamada M, Kagawa T, Kim SU, Miyao Y, Shimizu K, Mikoshiba K, Ikenaka K (1995) Expression of proteolipid protein gene is directly associated with secretion of a factor influencing oligodendrocyte development. J Neurochem 64:2396-2403.

Nave K-A, Lai C, Bloom FE, Milner RJ (1986) Jimpy mutant mouse: a 74 base deletion in the mRNA for myelin proteolipid protein and evidence for a primary defect in RNA splicing. Proc Natl Acad Sci USA 83:9264-9268.

Nixon RA (1982) Increased axonal proteolysis in myelin-deficient mutant mice. Science 215:999-1001.

Okano H, Masayuki M, Moriguchi A, Ikenaka K, Tsukada Y, Mikoshiba K (1987) Inefficient transcription of the myelin basic protein gene possibly causes hypomyelination in myelin-deficient mutant mice. J Neurochem 48:470-476.

Readhead C, Schneider A, Griffiths I, Nave K-A (1994) Premature arrest of myelin formation in transgenic mice with increased proteolipid protein gene dosage. Neuron 12:583-595.

Schneider A, Griffiths IR, Readhead C, Nave K-A (1995) Dominantnegative action of the jimpy mutation in mice complemented with an autosomal transgene for myelin proteolipid protein. Proc Natl Acad Sci USA 92:4447-4451.

Schubert D, Carlisle W, Look C (1975) Putative neurotransmitters in clonal cell lines. Nature 254:341-343. 
Skoff RP (1976) Myelin deficit in the jimpy mouse may be due to cellular abnormalities in astroglia. Nature 264:560-562.

Skoff RP, Knapp PE (1992) Phenotypic expression of X-linked genetic defects affecting myelination. In Myelin: biology and chemistry (Martenson RE, ed), pp 653-676. Boca Raton, FL: CRC.

Sommer I, Schachner M (1981) Monoclonal antibodies (O1 to O4) to oligodendrocyte cell surfaces: an immunocytological study in the central nervous system. Dev Biol 83:311-327.

Sundarraj N, Schachner M, Pfeiffer SE (1975) Biochemically differentiated mouse glial lines carrying a nervous system specific cell surface antigen (NS-1). Proc Natl Acad Sci USA 72:1927-1931.

Timsit S, Bally-Cuif L, Colman DR, Zalc B (1992) DM20 mRNA is expressed during the embryonic development of the nervous system of the mouse. J Neurochem 58:1172-1175.
Timsit S, Martinez S, Allinquant B, Peyron F, Puelles L, Zalc B (1995) Oligodendrocytes originate in a restricted zone of the embryonic ventral neural tube defined by DM20 mRNA expression. J Neurosci 15:1012-1024.

Weimbs T, Stoffel W (1992) Proteolipid protein (PLP) of CNS myelin: positions of free, disulfide-bonded, and fatty acid thioester-linked cysteine residues and implications for the membrane topology of PLP. Biochemistry 31:12289-12296.

Yamaguchi Y, Ikenaka K, Niinobe M, Yamada H, Mikoshiba K (1996) Myelin proteolipid protein (PLP), but not DM20, is an inositol hexakisphosphate-binding protein. J Biol Chem 271:27838-27846.

Yamamura T, Konola JT, Wekerle H, Lees MB (1991) Monoclonal antibodies against myelin proteolipid protein: identification and characterization of two major determinants. J Neurochem 57:1671-1680. 